\title{
Reproducibility of a method to evaluate the pelvic floor in normal pregnancy and puerperium using 3D ultrasound and 3D-Power Doppler angiography to assess endopelvic vascularization
}

Juan Troyano-Luque*1, Mercedes Febles Borges², Ana Isabel Padilla-Pérez ${ }^{1}$, Margarita Álvarez de la Rosa ${ }^{1}$, José Luis Trujillo-Carrilloํ, Salvatore Andrea Mastrolia ${ }^{1,3}$, Virginia Engels ${ }^{4}$, Luis San Frutos ${ }^{4}$, Tirso Pérez-Medina ${ }^{4}$

${ }^{1}$ Department of Obstertrics and Gynecology, Hospital Universitario de Canarias, Tenerife, Spain

${ }^{2}$ Department of Obstetrics and Gynecology, Hospital de Manacor, Mallorca, Spain

${ }^{3}$ Department of Obstetrics and Gynecology, Azienda Ospedaliero-Universitaria Policlinico di Bari, School of Medicine, University of Bari "Aldo Moro", Bari, Italy

${ }^{4}$ Department of Obstetrics and Gynecology, Hospital Universitario Puerta de Hierro, Madrid, Spain

Received: July 27, 2015

DOI: $10.5430 / j b g c . v 5 n 2 p 40$
Accepted: September 24, 2015 Online Published: September 27, 2015 URL: http://dx.doi.org/10.5430/jbgc.v5n2p40

\begin{abstract}
Introduction and hypothesis: We tested inter/intra-observer reproducibility of ten different three-D ultrasound (3D-US) pelvic floor variables and endopelvic vascularization using 3D-power Doppler angiography (3D-PDA) as a reliable method to assess pelvic floor status during pregnancy and puerperium. We hypothesized that the method would show good reproducibility.

Materials and methods: A prospective study was conducted in two university hospitals, with 162 nulliparous pregnant women evaluated at weeks 12, 28 and 36, and at 48 hours postpartum and three months post-delivery. At each visit, we performed transperineal 3D-US and 3D-PDA of the pelvic floor. Images corresponding to 30 cases were electronically sent between the 2 observers to test the reproducibility of the results.

Results: Correlation coefficients $>0.70$ for all 10 variables were obtained. Intra-observer reproducibility for each observer was very good, with intra-class correlation coefficients $>0.86$. Inter-observer reproducibility of urethral sphincter volume and vascularization, 3D-PDA, VI, FI and VFI measured by VOCAL technique with automatic threshold mode showed good correlation (ICC > 0.80), considered sufficiently high to be clinically applicable.

Conclusions: The present study showed good reproducibility and high inter- and intra-observer correlation coefficients for all the variables used to assess the pelvic floor during normal pregnancy and puerperium, including vaginal anterior wall anchors (AWA) as new biometric measures. This makes them reliable parameters for diagnosis and monitoring of pelvic floor disorders in normal pregnancies. We found that use of the VOCAL technique with automatic threshold mode for measurements was superior to the manual mode due to its accuracy and shorter time requirement.
\end{abstract}

Key Words: Three-dimensional ultrasound, Female pelvic floor, Prospective study, Anterior wall anchors, Reproducibility

*Correspondence: Juan Troyano-Luque; Email: jtroyanol@ sego.es; Address: Department of Obstetrics and Gynecology, University Hospital of Canary Islands, Ctra. Ofra, s/n, 38320, San Cristóbal de La Laguna, Santa Cruz de Tenerife, Spain. 


\section{Introduction}

Pregnancy and childbirth are the main causes of female pelvic floor dysfunction, and women with at least one delivery show pelvic floor disorders more frequently than nulliparous women. ${ }^{[1,2]}$ Impaired levator ani muscle function is responsible for most pelvic floor disorders, and the prevalence of symptomatic lesions of this muscle after vaginal delivery ranges from $15 \%$ to $35 \% .{ }^{[3]}$ In addition, increased urogenital hiatus during pregnancy and after delivery is associated to the distension of the levator ani. ${ }^{[4,5]}$

Factors such as multiparity, advanced maternal age, prolonged labor and fetal macrosomia are related with lesions in the elevator ani and the anal sphincter. ${ }^{[6-9]}$ Use of the forceps is associated with increased pubo-vesical muscle lesions and a higher incidence of anal sphincter tears. ${ }^{[6,10]}$ All these factors have been studied using three-dimensional ultrasound (3D-US) and by 3D-power Doppler angiography (3D-PDA) to determine the extent of such lesions and consequences arising during pregnancy as well as subsequent physiological implications. 3D-US is currently considered an important diagnostic tool in the assessment of the pelvic floor. ${ }^{[3,9]}$

The present study is the first part of a larger research project. Our group has developed a 10-parameter method using state-of-the-art ultrasound technology to assess pelvic floor parameters in women with normal pregnancy and puerperium. The method is intended for practical application in clinical practice where such technology is available, but the first step was to confirm its reproducibility.

\section{Objectives}

The objectives were to test inter and intra-observer reproducibility between two observers in different hospitals using 3D-US to evaluate female pelvic floor parameters in the three compartments (anterior, middle and posterior), and 3D-PDA to assess periurethral vascularization, throughout normal pregnancy and puerperium. We wished to analyze the reproducibility of measurable parameters, including the maximum height of vaginal anterior wall anchors (AWA). We hypothesized that the method proposed in the present study would be reproducible in different hospital settings.

\section{Material and methods}

A prospective multicenter study was conducted with the participation of the department of Obstetrics and Gynecology, Hospital de Manacor (Mallorca Island) and Hospital Universitario de Canarias in Tenerife (Canary Islands) between April 2012 and August 2013. The study design was approved in its entirety by the ethics committees of both hospitals. Inclusion and exclusion criteria for patients are shown in Table 1. The exclusion criteria were intended to avoid the inclusion of women with previous pelvic floor disorders that could interfere with the interpretation of data collected in the present study.

Table 1: Criteria for inclusion and exclusion in the study

Criteria for inclusion:
Caucasian, primiparous or miscarriage before 12 weeks of
pregnancy.
Singleton pregnancy.
Less than 12 weeks pregnancy at first visit: gestational age (GA)
estimated by ultrasound: CRL $\leq 52 \mathrm{~mm}$.
Informed consent to participate in the study.
Criteria for exlusion:
Present or past urinary or fecal incontinence.
History of pelvic surgery: hemorrhoids, anal fistulas, vaginal or
uterine surgery, anexectomy, myomectomy etc.
History of any kind of muscular or neurologic disease that could
cause weakness or paralysis of pelvic floor musculature.
Regular consumption of any medication or drugs that could affect
pelvic floor vascularization or musculature.

Of 174 women initially recruited, 12 were excluded: one elective abortion for Edwards syndrome, six did not attend the outpatient clinic after delivery or missed more than one visit before, and five because of poor quality volume images. The final study sample comprised 162 women.

\section{Study protocol}

Each patient was evaluated on five occasions; three times during pregnancy and twice after delivery, according to the following schedule (see Table 2).

Table 2: Evaluation schedule for each patient

1st visit before 12 weeks gestation (first trimester)
2nd visit at 28 weeks
3rd visit at 36 weeks
4th visit at 48 hours postpartum
5th visit at three months postpartum

At each of the five visits, the participants underwent 3D-US imaging of the pelvic floor and completed an internationally accepted questionnaire adapted for use in the present study. ${ }^{[11]}$

The ultrasound examinations were performed using a Voluson 730 Expert 3D multi-vaginal probe (3-9 MHz), GE Medical System (Kretztechnik GMBH, Zipf, Austria). Volume capture was performed by the same two observers (A and B) in each hospital, both of whom with over 20 years of professional experience, and with an interval of 24 hours between the two observers. Patients were scanned in the gynecologic lithotomy position with a bladder volume between $175 \mathrm{ml}$ and $200 \mathrm{ml}$, calculated by 3D-US. The scans were performed by transperineal route, inserting the probe in the introitus. Although the route was transperineal, we used a transvaginal probe for ease and versatility of use. Every examination had a time of renderization between 30 and 45 
seconds.

To obtain sagittal plane images, the probe was directed towards the abdominal wall of the patient at an angle of $30^{\circ}$ with respect to the longitudinal axis. After visualizing the three compartments of the pelvic floor in the same plane, the first volume was captured at rest (see Figure 1A and $1 \mathrm{~B})$. Then, without moving the probe, with the patient at rest, we selected the 3D-PDA option and captured the 3D image of the periurethral vasculature, with the following settings: ${ }^{[12]}$ Power (PWR): 100\% ; Gain: 7.4; Frequency: medium; Quality: High; Wall Filter: Low 1; Pulse repetition frequency (PRF): $0.6 \mathrm{KHz}$.

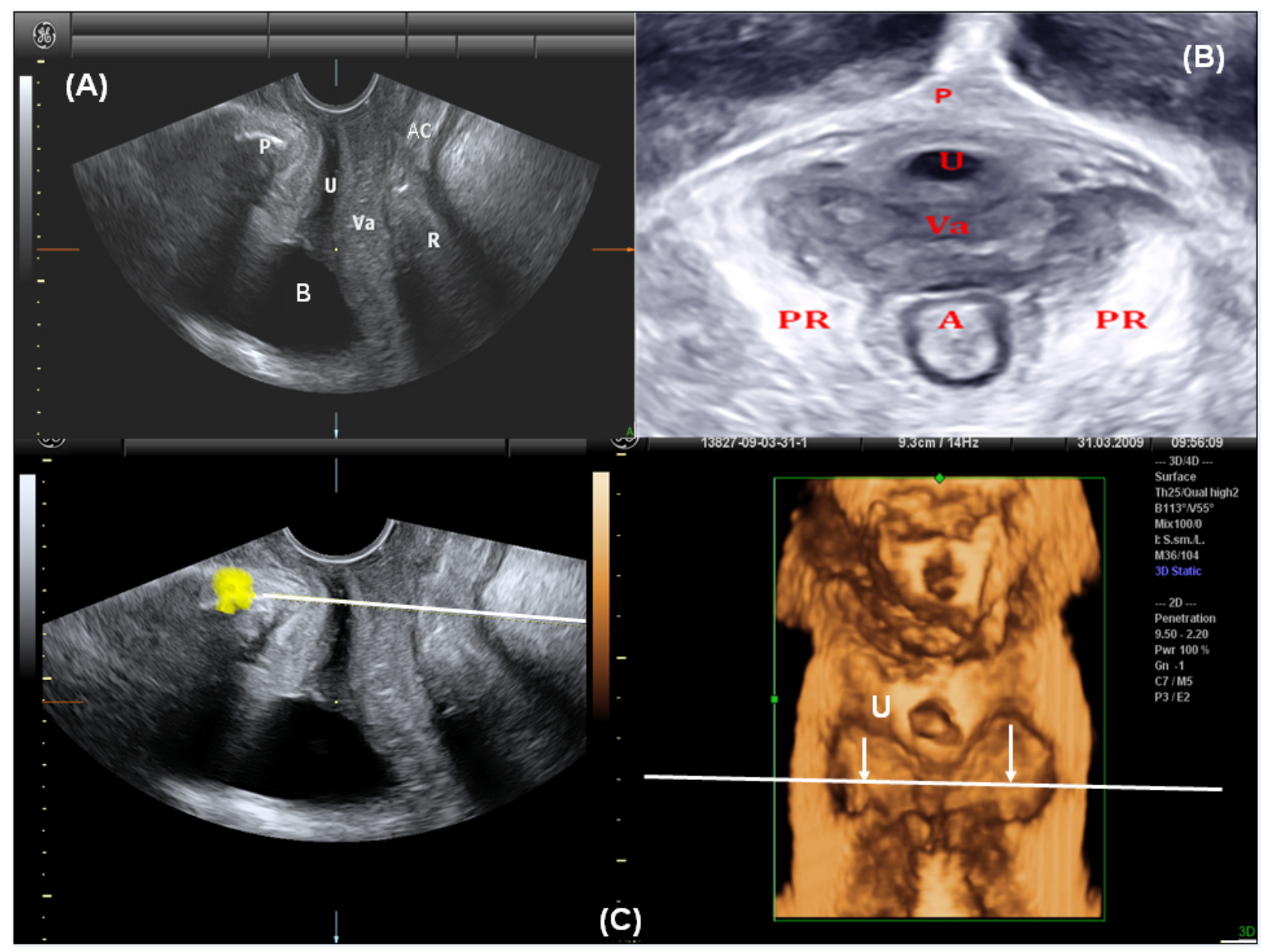

Figure 1: (A): Reference sagittal plane ultrasound image used in the study of the pelvic floor. P: Pubis; AC: Anal Canal; U: Urethra; Va: Vagina; R: Rectum. B: Bladder. (B): Three-dimensional ultrasound image of the urogenital hiatus. P: Pubis; U: Urethra; Va: Vagina; PR: Puborectalis muscle; A: Anus. (C): Measurements of vaginal anterior wall anchors maximum height: distance between the anchors and the lower edge of the urethra (U) (arrows).

Subsequently, to obtain the volume with the Valsalva maneuver, the image was captured at the point of maximum effort by the patient, while maintaining the same sagittal plane. Finally, to selectively study the posterior compartment, the probe was oriented perpendicular to the vaginal axis.

Four volumes of the pelvic floor were captured; three in the sagittal plane of reference for the analysis of the anterior and middle compartment as follows: one at rest, one with the Valsalva maneuver and a third evaluation of the pelvic floor (at rest) with 3D-PDA. The fourth volume was obtained in the coronal plane for the study of the posterior compartment.

In all cases we chose to use the VOCAL technique with automatic threshold VOCAL mode (TVM) to assess urethral sphincter volume and 3D-PDA vascularization indices (vascularization index [VI], flow index [FI] and vascularization flow index [VFI]), since this measurement mode is observerindependent ${ }^{[12]}$ and is less time-consuming than the manual VOCAL mode (MVM) as well as being more accurate. The variables studied for each patient are shown in Table 3 and Table 4. 
Table 3: Intra-observer reproducibility

\begin{tabular}{|c|c|c|c|c|c|}
\hline \multicolumn{2}{|c|}{ Parameter $^{\#}$} & Intra-class CC Observer A & 95\% CI Intra-class CC & Intra-class CC Observer B & 95\% CI intra-class CC \\
\hline \multicolumn{2}{|c|}{ UVA $\left(^{\circ}\right)$} & 0.963 & $0.923-0.983$ & 0.949 & $0.892-0.976$ \\
\hline \multirow{2}{*}{$\begin{array}{l}\text { USV } \\
(\mathrm{ml})\end{array}$} & MVM & 0.956 & $0.907-0.979$ & 0.923 & $0.838-0.963$ \\
\hline & TVM & 0.883 & $0.754-0.944$ & 0.969 & $0.936-0.985$ \\
\hline \multirow{2}{*}{ VI } & MVM & 0.989 & $0.977-0.995$ & 0.985 & $0.967-0.993$ \\
\hline & TVM & 0.986 & $0.972-0.994$ & 0.988 & $0.975-0.994$ \\
\hline \multirow{2}{*}{ FI } & MVM & 0.956 & $0.908-0.979$ & 0.905 & $0.800-0.955$ \\
\hline & TVM & 0.924 & $0.840-0.964$ & 0.973 & $0.942-0.987$ \\
\hline \multirow{2}{*}{ VFI } & MVM & 0.985 & $0.968-0.993$ & 0.971 & $0.939-0.986$ \\
\hline & TVM & 0.983 & $0.965-0.992$ & 0.993 & $0.985-0.997$ \\
\hline \multicolumn{2}{|c|}{ LHA $\left(\mathrm{cm}^{2}\right)$} & 0.885 & $0.758-0.945$ & 0.900 & $0.791-0.953$ \\
\hline \multicolumn{2}{|c|}{ AWA (mm) } & 0.958 & $0.912-0.980$ & 0.885 & $0.759-0.945$ \\
\hline \multicolumn{2}{|c|}{$\operatorname{ARA}\left({ }^{\circ}\right)$} & 0.864 & $0.714-0.935$ & 0.868 & $0.724-0.937$ \\
\hline
\end{tabular}

Table 4: Inter-observer reproducibility

\begin{tabular}{|c|c|c|c|}
\hline \multicolumn{2}{|c|}{ Parameter $^{\#}$} & Interclass CC & 95\% CI Interclass CC \\
\hline \multicolumn{2}{|c|}{ UVA $\left(^{\circ}\right)$} & 0.907 & $0.804-0.956$ \\
\hline \multirow{2}{*}{$\begin{array}{l}\text { USV } \\
\text { (ml) }\end{array}$} & MVM & 0.914 & 0.819-0.959 \\
\hline & TVM & 0.930 & $0.852-0.967$ \\
\hline \multirow{2}{*}{ VI } & MVM & 0.780 & $0.537-0.895$ \\
\hline & TVM & 0.877 & $0.741-0.941$ \\
\hline \multirow{2}{*}{ FI } & MVM & 0.704 & $0.377-0.859$ \\
\hline & TVM & 0.804 & $0.588-0.907$ \\
\hline \multirow{2}{*}{ VFI } & MVM & 0.790 & $0.559-0.900$ \\
\hline & TVM & 0.861 & $0.708-0.934$ \\
\hline \multicolumn{2}{|c|}{ LHA $\left(\mathrm{cm}^{2}\right)$} & 0.818 & $0.617-0.913$ \\
\hline \multicolumn{2}{|c|}{ AWA (mm) } & 0.865 & $0.715-0.936$ \\
\hline \multicolumn{2}{|c|}{$\operatorname{ARA}\left({ }^{\circ}\right)$} & 0.811 & $0.604-0.910$ \\
\hline
\end{tabular}

Note. UVA: urethrovesical angle; USV: urethral sphincter volume; MVM: Manual VOCAL mode; TVM: Threshold VOCAL mode; VI: vascularization index; FI: Flow index; VFI: vascularization flow index; LHA: length of hiatus area; AWA: vaginal anterior wall anchors (maximum height); ARA: anorectal angle.

In addition, each participant completed a questionnaire based on the "Consultation on Incontinence Questionnaire (ICIQ-UI-SF)".[13]

The procedure adopted for the study of intra- and interreproducibility for observers A and B was as follows:

From the total sample of 162 women evaluated by observer B (Mallorca), 30 cases were randomly selected. For each of these 30 cases, a good-quality 3-D ultrasound image of the pelvic floor was sent electronically to observer A (Tenerife), together with a 3D-PDA image reflecting endopelvic vasculature, within 24 hours of acquisition. The images contained no text that could reveal the identity of the patient and were coded by the sender.

(1) Each observer measured the 10 parameters twice: once for use in the analysis of inter-observer reproducibility, and again for use in the analysis of intraobserver reproducibility.

(2) Each observer recorded his/her results (also coded to preserve patient anonymity) on an Excel datasheet which was sent electronically to an independent collaborator (C) enlisted for the purpose.

(3) The collaborator sent the results to a statistician who performed (a) the analysis of intra-observer reproducibility on the basis of the two sets of measurements made by each observer, and (b) the comparative analysis of inter-observer reproducibility on the basis of the first measurements made for each case.

The reason for not reversing the dispatch of images (i.e. images were not sent from observer A to B) was that observer A was responsible for developing the 10-parameter method and wished to test its reproducibility in another hospital setting with similar ultrasound technology.

Regarding vaginal AWA as a biometric parameter in our study, assessment of the anchors was performed in the urogenital hiatus, measuring the maximum distance between the anchors and the lower edge of the urethral sphincter in the axial plane (see Figure 1C). In our experience, Tomographic Ultrasound Imaging (TUI) has proved an optimal method for measurement, allowing a $4 \times 4$ format with 15 slices $1.5 \mathrm{~mm}$ apart. With respect to the statistical method, a descriptive analysis of the variables was performed by calculating the mean and $95 \%$ confidence intervals, or medians and quartiles 1 and 3 depending on distribution. For comparisons, we used Student's $t$ test or the Mann-Whitney tests and ANOVA or Kruskal-Wallis test, depending on compliance with the requirements of each test. Spearman correlation coefficients were used to study the correlation between variables, and multivariate analysis was also performed us- 
ing multiple regression. All analyzes were carried out with SPSS 17.0 (SPSS Inc. Chicago, USA).

\section{Result}

Tables 3 shows intra-observer reproducibility for observer A and B while Table 4 shows inter-observer reproducibility. All 10 variables showed correlation coefficients greater than 0.70 , values that are considered acceptable. ${ }^{[14]}$

Intra-observer reproducibility for both observers $\mathrm{A}$ and B was very good, with intra-class correlation coefficients greater than 0.86 .

The inter-observer reproducibility in the case of urethral sphincter volume (USV) and the vascularization indices VI, FI and VFI, in our study, showed significantly lower intraclass correlation coefficients when measured by conventional MVM than when measured using automatic TVM, so it is preferable to use this method of measurement; in addition, TVM is less time-consuming than MVM. All the variables studied using TVM showed good inter-observer reproducibility, with ICC $>0.80$, values considered acceptable for clinical use (see Table 4).

\section{Discussion}

Although a host of methods have been used to explore the pelvic floor, ${ }^{[15]}$ the transperineal approach has been described by Dietz et al. ${ }^{[16]}$ as the most appropriate because it involves the least anatomical deformation, besides being more comfortable for the patient. But the authors used an abdominal probe which they considered would allow a better view of the three compartments. In our study, we used the transperineal route but with a three-dimensional vaginal probe. We understand that this offers a wide enough angle of insonation, which facilitates visualizing the three compartments in a single image, and is much more manageable due to its size. Still, we opted for independent volume capture of the posterior compartment, to ensure more accurate measurement of the anorectal angle.

For the assessment of ultrasound variables, most investigators ${ }^{[17]}$ recommend intermediate bladder filling, avoiding extreme volumes, and this was followed in our study, although some studies ${ }^{[17]}$ have shown that ultrasound variables are not affected by bladder volume. ${ }^{[18]}$ Finally, following the recommendations of Dietz at, ${ }^{[16]}$ we required that the rectal ampulla be empty for more accurate diagnosis. Regarding the ultrasound variables included in our study, we found several published studies that matched our method of measuring the posterior urethrovesical angle, the hiatal area, and the anorectal angle. However, for the urethral sphincter volume, periurethral vascularization and the maximum height of the vaginal anterior wall anchors, we found no published studies that employed the same method of measurement. ${ }^{[19]}$
With respect to assessment of the urethral sphincter, various studies, both in vitro and in vivo, have demonstrated the accuracy of 3D-US in estimating its volume, ${ }^{[20,21]}$ using the rotational planes pre-established by the VOCAL technique. ${ }^{[21]}$ In addition, the reliability of 3D-US has proven to be superior to that of two-dimensional ultrasound. Since the image is automatically obtained, the volume generated is operator-independent, but certain common patterns among different observers are required, to work with similar Cartesian values to ensure inter and intra-observer reliability and thus demonstrate the reproducibility of the method and results. ${ }^{[12]}$

Robinson et al. ${ }^{[22]}$ calculated urethral sphincter volume using 3D ultrasound but conducted the study in the early 1990s, and there have been great advances in 3D ultrasound technology since that time. Digesu et al. ${ }^{[23]}$ recently published a method for measuring the urethral sphincter using a vaginal 3D probe with transperineal access and a scanner similar to ours. Sphincter measurements were made in the axial plane, first manually tracing the area of the outer edge of the sphincter, and then a second area of the inner edge, in both cases measuring multiple planes $1 \mathrm{~mm}$ apart for the entire length of the sphincter. From these data, they calculated the volume automatically. Finally, to obtain the volume of the "rhabdosphincter", they subtracted the volume of the inner area from the total volume. The difference with our study is that they did not use the VOCAL rotational method, which we believe simplifies and shortens the process and increases accuracy due to the pre-established rotational planes.

Regarding periurethral vascularization, the exact relationship of the various 3D indices with actual blood flow is not fully known and is still being researched. However, these indices have proven reliable to assess vascularization. Various studies have reported reproducible results in the vascularization of complex structures such as the endometrium and the ovary, with very high intra- and inter-class correlation coefficients. ${ }^{[24]}$

Various investigators have studied female periurethral vascularization, but most employed 2D-US, ${ }^{[25]}$ and published their results on periurethral vascularization using 3D-PDA color histograms, with three vascular indices (VI, FI and VFI). However, the big difference with our study is that they took as the periurethral area a threshold of $5 \mathrm{~mm}$ instead of $3 \mathrm{~mm}$ which we used in our study. Considering the anatomical distribution of urethral vascularization shown by Doppler flow maps, it seems that beyond $3 \mathrm{~mm}$ one begins to include vessels of the vaginal wall, so including tissue beyond this limit only contaminates the results.

With respect to the vaginal anterior wall anchors, many authors have described images of paravaginal defects of the urogenital hiatus observed in the axial plane. ${ }^{[26,27]}$ These studies have focused only on describing the shape of the an- 
chors. Moreover, correlation with the clinical examination of patients has been questioned due to poor reproducibility. We present a new numerical parameter, not a subjective impression of these anchors, measuring the maximum height they presented before and after delivery. Very precise measurements were obtained using TUI mode with multiple slices just $1 \mathrm{~mm}$ apart.

In the analysis of the reproducibility of our measurements, to refer to the urethrovesical angle (UVA), we relied on previously published criteria, ${ }^{[18]}$ obtaining good intraand inter-class correlation coefficients. Duckett and Lautmann ${ }^{[28]}$ have reported the reproducibility of results in patients before and after undergoing anterior colporrhaphy. They used the same method of measurement and the same statistical program, obtaining even slightly higher values than ours (intra-class CC 0.999 and inter-class CC 0.998). Digesu and $\mathrm{al}^{[23]}$ also reported good reproducibility of results in measuring the volume of the urethral sphincter, with high rates of reproducibility for the rhabdosphincter (intra-class CC: 0.945; inter-class CC: 0.896), very close but slightly inferior to ours (intra-class CC: 0.969; inter-class CC 0.93).

For periurethral vascularization, a good correlation was obtained with CC greater than 0.80 in all vascular indices using the threshold mode. These results are comparable to those reported by other authors, ${ }^{[25]}$ although they only reported finding small differences between the two repeated measurements by the same examiner, without specifying the correlation coefficient values or inter-observer reproducibility.

Our method of calculating the hiatal area has been described previously ${ }^{[19]}$ and its reproducibility has been confirmed. ${ }^{[29]}$ In this regard, Weinstein et al. ${ }^{[15]}$ found excellent intraobserver reproducibility (ICC: 0.98 ) on measuring the hiatal area with the patient at rest. Also, in the work presented by Santoro et al., ${ }^{[29]}$ intra-class correlation coefficients for the same parameter were good, ranging from 0.857 to $0.893 \mathrm{ac}-$ cording to observers, which are very close to ours $(0.885$ for observer A and 0.900 for observer B); similarly, our interobserver reproducibility (ICC: 0.818 ) falls within the range presented by Santoro et al (ICC: 0.783-0.851).

In the case of the maximum height of vaginal anterior wall anchors, we found very good intra-observer reproducibility (ICC: 0.95 and 0.88) and inter-observer reproducibility
(ICC: 0.86). These results imply high reliability for this parameter, so we believe it should be considered as another useful parameter for the study of the pelvic floor.

The anorectal angle (ARA) was also reproducible in our study, although it presented the lowest correlation coefficients of all parameters (ICC: 0.864 and 0.969 and 0.811 for intra-observer and inter-observer reproducibility). This may reflect the difficulty others have also had to clearly identify the posterior wall of the rectal ampulla. Santoro et al. ${ }^{[29]}$ used a different method than ours, as they measured the angle formed by the posterior wall of the rectum and the anal canal posterior edge. In our case, we took as a reference the line passing through the axis of the anal canal. Constantini ${ }^{[18]}$ presented a method to measure ARA similar to ours, showing good intra- and inter-observer reproducibility with the patient at rest, although they did not report the intra and inter-class correlation coefficients.

\section{Strengths and limitations of the study}

This study showed good reproducibility and high inter- and intra-observer correlation coefficients for all the variables used to assess the pelvic floor during normal pregnancy and puerperium, making them reliable parameters for diagnosis and monitoring of pelvic floor disorders in normal pregnancies. Moreover, the employment of the techniques described above requires personnel with recognized expertise in the field of pelvic floor ultrasound and physiology.

\section{Conclusions}

All the ultrasound variables that we evaluated proved to be reproducible, with high correlation coefficients. The evaluation of these parameters, as we will discuss in imminent paper, can help identify patients at risk of pelvic floor dysfunction after changes occurring during normal pregnancy and medium-term puerperium.

We established a new objective parameter for clinical application, namely maximum height of vaginal AWA. This can be measured with great precision to reflect biometric changes in normal pregnancy and puerperium, and in the present study it showed good reproducibility.

\section{Conflicts of Interest Disclosure}

The authors declare no conflict of interest.

\section{References}

[1] Liu J, Guaderrama N, Nager CW, et al. Functional correlates of anal canal anatomy: puborectalis muscle and anal canal pressure. Am J Gastroenterol. 2006; 101(5): 1092-7. PMid: 16606349. http: //dx.doi.org/10.1111/j.1572-0241.2006.00596.x

Published by Sciedu Press
[2] Milsom I, Ekelund P, Molander U, et al. The influence of age, parity, oral contraception, hysterectomy and menopause on the prevalence of urinary incontinence in women. J Urol. 1993; 149(6): 1459-1462. PMid: 8501788.

[3] Dietz HP. Quantification of major morphological abnormalities of the levator ani. Ultrasound Obstet Gynecol. 2007; 29(3): 329-34. 
PMid: 17323308. http://dx.doi.org/10.1002/uog. 3951

[4] Svabik K, Shedk KL, Dietz HP. How much does the levator hiatus have to stretch during child-birth? BJOG. 2009; 116: $1657-$ 62. PMid: 19735376. http://dx.doi.org/10.1111/j.1471-0 528.2009.02321. $\mathrm{x}$

[5] Shek KL, Dietz HP. The effect of Childbirth on hiatal dimensions Obstet Gynecol. 2009; 113(6): 1272-8. PMid: 19461422. http: //dx.doi.org/10.1097/AOG.0b013e3181a5ef 23

[6] Christianson LM, Bovbjerg VE, McDavitt EC, et al. Risk factors for perineal injury during delivery. Am J Obstet Gynecol. 2003; 189(1): 255-60. PMid: 12861171. http://dx.doi.org/10.1067/mob. 2 003.547

[7] Kearney R, Miller JM, Ashton-Miller JA, et al. Obstetric factors associated with levator ani muscle injury after vaginal birth. Obstet Gynecol. 2006; 107(1): 144-9. PMid: 16394052. http://dx.doi .org/10.1097/01.AOG.0000194063.63206.1c

[8] Alouini S, Rossard L, Lemaire B, et al. Anal sphincter tears after vaginal delivery: risks factors and means of prevention. Rev Med Liege. 2011; 66(19): 545-9. PMid: 22141262.

[9] Krofta L, Otcenásek M, Kasíková E, et al. Pubococcygeuspuborectalis trauma after forceps delivery: evaltuation of the levator ani muscle with 3D/4D ultrasound. Int Urogynecol J Pelvic Floor Dysfunct. 2009; 20(10): 1175-81. PMid: 19639235. http: //dx.doi.org/10.1007/s00192-009-0837-6

[10] Dandolu V, Chatwani A, Harmanli O, et al. Risk factors for obstetrical anal sphincter lacerations. Int Urogynecol J Pelvic Floor Dysfunct. 2005; 16(4): 304-7. PMid: 15809773. http://dx.doi.org /10.1007/s00192-005-1297-2

[11] Timmermans L, Falez F, Mélot C, et al. Validation of use of the International Consultation on Incontinence Questionnaire-Urinary Incontinence-Short Form (ICIQ-UI-SF) for impairment rating: a transversal retrospective study of 120 patients. Neurourol Urodyn. 2013 Sep; 32(7): 974-9. http://dx.doi.org/10.1002/nau.2 2363

[12] Grupo Misus. Documentos de consenso sobre ecografía y angiografía Doppler 3D en obstetricia y ginecología. En: Mercé LT. Ecografía Total en obstetricia y ginecología. Madrid (Spain): Ed. Marbán. 2009. 370-92p.

[13] Avery K, Donovan J, Peters TJ, et al. ICIQ: a brief and robust measure for evaluating the symptoms and impact of urinary incontinence. Neurourol Urodyn. 2004; 23(4): 322-30. PMid: 15227649. http://dx.doi.org/10.1002/nau. 20041

[14] Burdock EI, Fleiss JL, Hardesty AS. A new view of interobserver agreement. Per Psychol. 1963; 16: 373-84. http://dx.doi.org /10.1111/j.1744-6570.1963.tb01283.x

[15] Weinstein MM, Jung SA, Pretorius DH, et al. The reliability of puborectalis muscle measurements with 3-dimensional ultrasound imaging. Am J Obstet Gynecol. 2007; 197(1): 68.e1-6. PMid: 17618762. http://dx.doi.org/10.1016/j.ajog. 2007 .02 .041

[16] Dietz HP. Pelvic floor ultrasound: Basic physics, instrumentation and examination technique. In: Dietz HP, Hoyte L, Steensma AB. Atlas of pelvic floor ultrasound. London: Springer; 2008. 23-29p. http://dx.doi.org/10.1007/978-1-84628-584-4_2

[17] Mouritsen L, Bach P. Ultrasonic evaluation of bladder neck position and mobility: the influence of urethral catheter, bladder volume, and body position. Neurourol Urodyn. 1994; 13(6): 637-46. PMid: 7697055. http://dx.doi.org/10.1002/nau.1930130603

[18] Costantini S, Esposito F, Nadalini C, et al. Ultrasound imaging of the female perineum: the effect of vaginal delivery on pelvic floor dynamics. Ultrasouund Obstet Gynecol. 2006 Feb; 27(2): 183-7. PMid: 16388512. http://dx.doi.org/10.1002/uog. 2663

[19] Dietz H, Shek K, Clarke B. Biometry of the pubovisceral muscle and levator hiatus by three-dimensional pelvic floor ultrasound. U1trasound Obstet Gynecol. 2005; 25: 580-5.ç.

[20] Raine-Fenning NJ, Clewes JS, Kendalll NR, et al. The interobserver reliability and validity of volumen calculation from threedimensional ultrasound datasets in the in Vitro stting. Ultrasound Obstet Gynecol. 2003; 21(3): 283-91. PMid: 12666225. http: //dx.doi.org/10.1002/uog.61

[21] Farrell T, Leslie JR, Chien PF, et al. The realiability and validity of three dimensional ultrasound volumetric measurements using an in vitro balloon and in vivo uterine model. BJOG. 2001; 108(6): 57382. PMid: 11426890. http://dx.doi.org/10.1111/j.1471-0 528.2001.00148.x

[22] Robinson D, Toozs-Hobson P, Cardozo L, et al. Correlating structure and function three-dimensional ultrasound of the urethral sphincter. Ultrasound Obstet Gynecol. 2004; 23: 272-76. PMid: 15027017. http://dx.doi.org/10.1002/uog. 987

[23] Digesu GA, Calandrini N, Derpapas A, et al. Intraobserver and interobserver reliability of the three-dimensional ultrasound Imaging of female urethral sphincter using a translabial technique. Int Urogynecol J. 2012; 23(8): 1063-8. PMid: 22270730. http://dx.doi . org/10.1007/s00192-012-1669-3

[24] Mercé LT, Alcázar JL, Engels V, et al. Endometrial volume and vascularity measurements by transvaginal three-dimensional ultrasonography and power Doppler angiography in stimulated and tumoral endometria: intraobserver reproducibility. Gynecol Oncol. 2006; 100(3): 544-50. PMid: 16243383. http://dx.doi.org/1 $0.1016 / j$. ygyno.2005.09.024

[25] Wieczorek AP, Wozniak MM, Stankiewicz A, et al. Quantitative assessment of urethral vascularity in nulliparous females using highfrequency endovaginal ultrasonography. World J Urol. 2011; 29(5): 625-32. PMid: 21796481. http://dx.doi.org/10.1007/s0034 5-011-0732-x

[26] Dietz HP, Steensma AB, Hastings R. Three-dimensional ultrasound imaging of the pelvic floor: the effect of parturition on paravaginal support structures. Ultrasound Obstet Gynecol. 2003; 21: 589-95. PMid: 12808677. http://dx.doi.org/10.1002/uog.100

[27] Dietz HP, Pang S, Korda A, et al. Paravaginal defects: a comparison of clinical examination and 2D/3D ultrasound imaging. Aust NZ J Obstet Gynecol. 2005; 45: 187-190. PMid: 15904441. http: //dx.doi.org/10.1111/j.1479-828X.2005.00377.x

[28] Duckett J, Lautmann K. Ultrasound changes in the relationship between the urethra and bladder neck caused by prolapse repair: feasibility and reliability of measurements. J Obstet Gynaecol. 2012 Oct; 32(7): 672-5. http://dx.doi.org/10.3109/01443615. 2012.711390

[29] Santoro GA, Wieczorek AP, Shobeiri SA, et al. Interobserver and interdisciplinary reproducibility of 3D endovaginal ultrasound assessment of pelvic floor anatomy. Int Urogynecol J. 2011 Jan; 22(1): 53-9. http://dx.doi.org/10.1007/s00192-010-1233-y 